\title{
Examination of useful items for the assessment of fall risk in the community-dwelling elderly Japanese population
}

\author{
Shinichi Demura · Susumu Sato • \\ Tomohisa Yokoya • Toshiro Sato
}

Received: 1 June 2009/Accepted: 12 November 2009/Published online: 16 December 2009

(C) The Japanese Society for Hygiene 2009

\begin{abstract}
Objectives The aim of this study was to select useful items for assessing fall risk in healthy elderly Japanese individuals.

Methods A total of 965 healthy elderly Japanese subjects aged $\geq 60$ years (349 males $70.4 \pm 7.1$ years, 616 females $69.9 \pm 7.1$ years) participated in this study. Of these, $16.6 \%$ had suffered from a previous fall. We assumed five fall risk factors: symptoms of falling, physical function, disease and physical symptoms, environment, and behavior and character. Eighty-six items were selected to represent these factors. To confirm the component items for each risk factor, we performed factor analysis (principle factor solution and varimax rotation). The high-fall risk response rate was also calculated for each item, and significant differences in this rate were examined between groups of those who had and not had experienced a fall.
\end{abstract}

\footnotetext{
S. Demura

Kanazawa University, Kanazawa, Ishikawa, Japan

S. Sato $(\bowtie)$

Life-Long Sports Core, Kanazawa Institute of Technology,

7-1 Ohgigaoka, Nonoichi, Ishikawa 921-8501, Japan

e-mail: sssato@neptune.kanazawa-it.ac.jp

T. Yokoya

Kaga City Hall, Kaga, Ishikawa, Japan

T. Sato

Niigata University of Health and Welfare,

Niigata, Niigata, Japan
}

Results Useful items were selected using the following criteria: (1) items showing a significant difference in high fall risk response rate between faller and non-faller groups were selected as useful items; (2) items showing low factor loading $(<0.4)$ for any factor were deleted as inappropriate items; (3) the top two items showing a greater amount of the difference in high fall risk response rate among the representative items for each factor. A total of 50 items were selected from each fall risk factor (symptoms of falling, 3 items; physical function, 22 items; disease and physical symptom, 13 items; environment, 4 items; behavior and character, 8 items).

Conclusions Based on our results, the selected items can comprehensively assess the fall risk of a healthy elderly Japanese population. In addition, the assessment items for physical function comprised items of different levels of difficulty, and these are able to gradually and comprehensively assess physical function.

Keywords Community-dwelling elderly · Factor analysis · Item analysis · Prevention fall · Risk factors

\section{Introduction}

Fall prevention in the elderly is an important social issue and has received a great deal of attention [1-4]. In Japan, a fall risk assessment chart recently developed by the Tokyo Metropolitan Institute of Gerontology (TMIG) has been widely used $[5,6]$ to multilaterally evaluate fall risk in the elderly. This chart uses risk factors of physical function (walking ability, muscular strength, balancing), disease, medication, environment, sight and hearing disease, and fall anxiety and is characterized by setting a screening criteria for high fall risk subjects (total score $\geq 5$ ) $[5,6]$. 
The term fall risk means the possibility of falling in the future, and it is preferable that outcomes of fall risk assessment provide not only the level of fall risk but also prevention measures and treatments for individuals. Although the TMIG assessment chart can determine fall risk level based on its criteria for screening persons with high fall risk, there are problems in evaluating the fall risk profile (problems for individuals) within the context of preventing falling after a few years.

To identify the fall risk profile and determine the necessary prevention measures and treatments, it is important that a comprehensive assessment of fall risk be carried out using multiple risk factors and that the risk level and risk characteristics for each risk factor be determined. Previous studies have indicated several risk factors, such as fall experience, decline in physical function, disease, external environment, behavioral and psychological characteristics, as predictors of risks of falling [7-9]. Although the TMIG assessment chart is composed of 15 items from multiple factors, there are only a few items on physical function (4 items), external environment (1 item), and psychology (1 item), as opposed to seven items on disease. Therefore, the TMIG chart is limited in its comprehensive assessment of fall risk, and it is difficult to determine risk level and risk characteristics of each factor because of the large number of assessment items.

However, longitudinal (follow-up) and cross-sectional assessments of fall risk are also important because fall risk means the possibility of a fall in the future. In the longitudinal assessment, it is preferable that changeable risk factors (such as physical function, activity, behavior) and unchangeable risk factors (such as chronic disease, fall experience) are separately assessed and that the characteristics of the changeable risk factors are followed up [10]. Although it is to be expected that measurements for preventing falls in the healthy elderly are mainly designed to improve physical function, in this context the TMIG assessment chart is limited because it contains few assessment items on physical function [11-14]. The healthy elderly population demonstrates a broad range of physical function levels and, consequently, it is particularly important that both physical functions and the functional level of each physical function component are comprehensively assessed. This criterium indicates that a comprehensive and gradual assessment of physical function is important to prevent falls in the healthy elderly population.

Given that the existing fall risk assessment chart commonly used in Japan has several inherent problems, it is desirable to develop another assessment chart that takes these problems into account. The aim of the study reported here was to examine useful items for assessing fall risk in a healthy elderly Japanese population.

\section{Method}

Subjects and data collection

The subjects participating in the study were healthy, community-dwelling elderly aged $\geq 60$ years who were living in Akita, Kanagawa, Ishikawa, Fukui, Nagano, Gifu, Aichi, Tottori, and Fukuoka Prefectures. Mail or field surveys were conducted between November 2007 and May 2008 in which 1770 elderly were approached as potential participants; of these, 1317 responded. We enclosed or presented a letter explaining the aim and design of the study to each subject and subsequently obtained their written informed consent.

Among these 1317 potential subjects, 965 (mean age $70.1 \pm 7.1$ years) had missing values of $<10 \%$ and were therefore accepted as subjects of the study. The study population consisted of 349 males (mean age $70.4 \pm 7.1$ years) and 616 females (mean age $69.9 \pm 7.1$ years). Among the subjects, $160(16.6 \%)$ had had a fall experience in the past year (faller) and 805 had no experience of fall in the past year (non-faller). This fall incidence was comparable with those reported in previous studies for the community-dwelling Japanese elderly $[5,6,11,12]$.

\section{Fall risk assessment}

Important attributes of any fall risk assessment of the healthy elderly population are that the outcomes of the fall risk assessment based on comprehensive risk factors of falls provide a fall risk level and fall risk profile and that a strategy for the prevention of falls in individuals can be determined. Based on the results of earlier studies examining risk factors that induced falls in the elderly [3, 7-9], we chose five fall risk factors-symptoms of falling, physical function, disease and physical symptoms, environment, and behavior and character-to comprehensively assess fall risk in our elderly population.

"Symptoms of falling" (or sign of a fall) refers to falling easily (the state of being liable to fall), and it is a concept associated with the occurrence of warning symptoms similar to falls, such as a stumble. Since earlier studies have indicated that a current fall is one of the important predictors of recurrent falling $[3,7,8]$, we considered that the occurrence of warning symptoms of a fall is important to screen fall risk level. We therefore assumed it to be one of the risk factors and set three items.

This study assumed two factors of "physical function" and "disease and physical symptoms" as internal risk factors. Decline of physical function and the accompanying change in gait and walking ability are important risk factors, and their contributions to falls in the elderly are high. Further, since these factors provide valuable information 
for determining an appropriate fall prevention strategy, they should be evaluated multilaterally. This study assumed eight sub-factors: balancing, muscular strength, lower limb strength, walking ability, gait, going up and down the stairs (stepping the stairs), holding and changing a posture, and upper limb function. Forty items were set to represent these sub-factors.

In terms of diseases and physical symptoms, we study assumed nine sub-factors of dizziness and blackout, medication, cerebral vascular disease, arthritic disease, bone disease, circulatory disease, metabolic disease, seeing and hearing disorder, cognition disorder, and others, and selected 17 items from these sub-factors. Although a low prevalence of these diseases is expected in the case of the non-handicapped community-dwelling elderly, comprehensive assessment of disease and physical symptoms is essential for determining the risk profile of an individual.

We also assumed two external risk factors of "environment" and "behavior and character". Although the impact of external risk factor on falls is considered to differ according to the level of physical function, it is important to develop a fall prevention strategy for individuals that relates to their risk level due to external factors. In the case of environmental factors, there may be risk factors which can be easily improved by instruction. This study assumed two sub-factors of the surrounding environment and clothing in the environmental factor category and selected eight items. Further, inactivity, risk behavior, character, and fear of falling were all assumed to be sub-factors in behavior and character, and we selected 18 items.

The preference was given to simplicity, and all questions could be answered using a dichotomous scale (yes or no). The response with a high risk category for each question was considered to be a "high-risk response".

\section{Statistical analyses}

In this study of fall risk assessment among the community-dwelling elderly, we assumed five fall risk factors and several component factors (sub-factors), selecting items representing each risk factor by considering previous studies. However, it is statistically unclear how these items can be classified into each component factor (subfactor).

Therefore, to comprehensively assess fall risk, we statistically classified the items which were selected logically in this study by using factor analysis (step 1). In general, factor analysis is a statistical tool used for extracting the abstract concept underlying a interrelationship among items as a factor based on the correlation matrix. This study, as a first step, statistically confirmed the suitability of the component factor and its representative items for each risk factor to comprehensively assess fall risk by factor analysis.

We then attempted to select more useful items to assess fall risk among the items representing each risk factor (step 2). Factor loading, which is calculated in factor analysis, is a statistic showing the relationship between each component item and each extracted factor, but is not a statistic showing the relationship between each component item and fall risk. Therefore, we used the difference in the rate of high-risk response between faller and non-faller groups as an external criterion showing the relationship between each component item and fall risk. That is, we assumed that the greater the difference in the rate of high-risk response, the more useful the item would be for fall risk assessment. Statistical procedures in each step were as follows.

\section{Confirmation of component items of each risk factor (step 1)}

To confirm the relationship between the fall risk assessment items and risk factors assumed in this study (to statistically confirm component items of each risk factor), we performed a factor analysis for each risk factor (symptoms of falling, physical function, disease and physical symptoms, environment, and behavior and character). Extraction of factors was based on the principal factor solution and normal varimax rotation, and each factor was interpreted considering factor loading. Scree-polt and factor loading matrix were considered in determining the number of factors.

\section{Selection of useful items for assessment of fall risk (step 2)}

This study selected useful items to assess fall risk based on the following procedures.

1. Significant difference in the rate of high fall risk response for each item was tested between faller and non-faller groups. The significance level was adjusted by Bonferroni's method. If a significant difference was found, the item was considered to be useful.

2. In the factor analysis for each risk factor, the items showing low factor loading $(<0.40)$ for any factor were deleted as inapplicable.

3. Differences in rate of high fall risk response were calculated between faller and non-faller groups (faller minus non-faller group). Among the representative items for each factor [showing high factor loading $(\geq 0.40)]$, the top two items showing a larger amount of difference in the rate of high fall risk response were useful for assessing each risk factor. 


\section{Results}

Component items of each risk factor

\section{Symptoms of falling}

Table 1 shows the results of the factor analysis for the risk factor "symptoms of falling". One factor explaining 55\% of the variance was extracted as were all items showing high factor loading (more than 0.70). Significant differences in the percentage of high fall risk response were found in all three extracted items, and these three items were selected as being useful indicators of symptoms of falling.

\section{Physical function}

Table 2 shows the results of the factor analysis for the risk factor "physical function". Three factors explaining $43.1 \%$ of the variance were extracted. For the physical function factor, we assumed the sub-factors of balancing, muscular strength, lower limb strength, walking ability, going up and down stairs, gait, holding and changing posture, and upper limb function. However, these sub-factors, with the exception of gait, were not extracted as dependent factors, and both the first and second factors were composed of items representing multiple sub-factors (muscular strength, balancing, walking ability, gait, going up and down stairs, holding and changing posture, upper limb function). Among the representative items, the first factor showed higher factor loading with the items associated with relatively less difficult physical activities, and the second factor showed higher factor loading with items associated with relatively more difficult physical activities. Therefore, we interpreted the first factor as the "fundamental function factor", and the second factor as the "advanced function factor." The third factor showed higher factor loading with items associated with gait, and we interpreted it as the "gait factor".
Useful items for assessing fall risk for the elderly were then selected from the representative items of each physical function factor. As mentioned above, in the factor analyses, only the third factor (gait factor) was interpreted to be an independent factor reflecting the sub-factors assumed in this study, while the other two factors, which were characterized by the difficulty of the physical activities, were extracted. Since physical function in fall risk assessment should be assessed comprehensively, two items showing a greater difference in high fall risk response between faller and non-faller groups were selected from representative items of each sub-factor. In the first factor (fundamental function factor), ten items were selected from the five subfactors of muscular strength, balancing, walking ability, going up and down stairs, lower limb strength, holding and changing posture, and upper limb function. There is only one item belonging to the following sub-factors of lower limb strength, going up and down stairs, holding and changing posture, and upper limb function. Items associated with gait were excluded from the items of the first factor because gait was interpreted as the third factor. Similarly, in the second factor, ten items representing each sub-factor were selected. In the third factor, two items associated with gait were selected.

\section{Disease and physical symptoms}

Table 3 shows the results of the factor analysis for the risk factor "disease and physical symptoms". Six factors explaining $54.8 \%$ of variance were extracted. Taking the factor loading matrix into account, these factors were interpreted as dizziness and blackout (the first factor), medication (the second factor), seeing/hearing and cognition disorder (the third factor), cerebral vascular (the fourth factor), arthritic and bone disease (the fifth factor), and circulatory disease (the sixth factor). The two items (sleep disorder and fainting) did not show high factor loading with any factor. We selected the top two items in terms of

Table 1 The results of factor analysis on symptoms of falling

\begin{tabular}{|c|c|c|c|c|c|}
\hline \multirow[t]{2}{*}{ Items } & \multicolumn{2}{|l|}{ Factor analysis } & \multicolumn{3}{|c|}{ High-fall risk rate } \\
\hline & Factor loading $(\mathrm{F} 1)$ & Communality & Non-faller $(\%)$ & Faller $(\%)$ & Difference $(\%)$ \\
\hline Feel like falling in the preceding year ${ }^{\mathrm{a}}$ & -0.717 & 0.147 & 29.8 & 83.4 & $53.6^{*}$ \\
\hline Stumble $^{\mathrm{a}}$ & -0.789 & 0.204 & 11.2 & 37.1 & $25.9^{*}$ \\
\hline Look like falling (third-party evaluation) ${ }^{\mathrm{a}}$ & -0.717 & 0.147 & 3.2 & 23.4 & $20.2 *$ \\
\hline Eigenvalue & 1.65 & & & & \\
\hline Accumulative contribution & $55.0 \%$ & & & & \\
\hline
\end{tabular}

Values in italics mean representative items of each factor

F1, Symptom of fall

$* P<0.05$

a Selected items as useful items 
Table 2 The result of factor analysis on physical function

\begin{tabular}{|c|c|c|c|c|c|c|c|c|}
\hline \multirow[t]{3}{*}{ Items } & \multirow[t]{3}{*}{ Sub-factor } & \multicolumn{4}{|c|}{ Factor analysis } & \multicolumn{3}{|c|}{ High-fall risk rate } \\
\hline & & \multicolumn{3}{|c|}{ Factor loading } & \multirow[t]{2}{*}{ Communality } & \multirow{2}{*}{$\begin{array}{l}\text { Non-faller } \\
(\%)\end{array}$} & \multirow{2}{*}{$\begin{array}{l}\text { Faller } \\
(\%)\end{array}$} & \multirow{2}{*}{$\begin{array}{l}\text { Difference } \\
(\%)\end{array}$} \\
\hline & & $\mathrm{F} 1$ & $\mathrm{~F} 2$ & F3 & & & & \\
\hline Wringing out a wet towel ${ }^{\mathrm{a}}$ & Muscular strength & 0.446 & 0.078 & 0.106 & 0.314 & 4.6 & 16.6 & $12.0 \mathrm{~ns}$ \\
\hline Carrying (about $5 \mathrm{~kg})^{\mathrm{a}}$ & Muscular strength & 0.702 & 0.157 & 0.064 & 0.529 & 7.4 & 18.9 & $11.5 \mathrm{~ns}$ \\
\hline Bucket of water & Muscular strength & 0.580 & 0.115 & 0.028 & 0.358 & 4.8 & 13.7 & $8.9 \mathrm{~ns}$ \\
\hline $\begin{array}{l}\text { Folding up and down a light futons } \\
\text { or blanket (light futon) }\end{array}$ & Muscular strength & 0.603 & 0.098 & 0.028 & 0.377 & 4.8 & 13.1 & $8.3 \mathrm{~ns}$ \\
\hline Jumping a (approx.) 30-cm ditch ${ }^{\mathrm{a}}$ & Lower limb strength & 0.762 & 0.152 & 0.158 & 0.635 & 9.1 & 23.4 & $14.3 \mathrm{~ns}$ \\
\hline $\begin{array}{l}\text { Standing from sitting posture(Seiza) with } \\
\text { hands on the floor }^{\mathrm{a}}\end{array}$ & $\begin{array}{l}\text { Changing and holding } \\
\text { posture }\end{array}$ & 0.476 & 0.041 & 0.226 & 0.325 & 6.5 & 16.0 & $9.5 \mathrm{~ns}$ \\
\hline $\begin{array}{l}\text { Buttoning or unbuttoning a shirt (quickly } \\
\text { with hands) }\end{array}$ & Upper limb function & 0.476 & 0.331 & 0.156 & 0.392 & 14.0 & 25.7 & $11.7 \mathrm{~ns}$ \\
\hline $\begin{array}{l}\text { Climbing up stairs slowly without a handrail } \\
\text { or wall }\end{array}$ & $\begin{array}{l}\text { Going and down } \\
\text { stairs }\end{array}$ & 0.653 & 0.102 & 0.304 & 0.554 & 9.7 & 26.3 & $16.6 \mathrm{~ns}$ \\
\hline Putting on a sock while standing ${ }^{\mathrm{a}}$ & Balancing ability & 0.553 & 0.265 & 0.283 & 0.487 & 15.6 & 37.7 & $22.1 \mathrm{~ns}$ \\
\hline Standing with one foot (about $5 \mathrm{~s})^{\mathrm{a}}$ & Balancing ability & 0.606 & 0.227 & 0.137 & 0.537 & 10.9 & 29.1 & $18.2 \mathrm{~ns}$ \\
\hline $\begin{array}{l}\text { Putting on pants or a skirt while standing } \\
\text { without holding an object }\end{array}$ & Balancing ability & 0.585 & 0.313 & 0.273 & 0.554 & 14.8 & 32.0 & $17.2 \mathrm{~ns}$ \\
\hline $\begin{array}{l}\text { One foot balance with open eyes (about 10- } \\
20 \mathrm{~s} \text { ) }\end{array}$ & Balancing ability & 0.685 & 0.241 & 0.187 & 0.633 & 11.8 & 28.0 & $16.2 \mathrm{~ns}$ \\
\hline $\begin{array}{l}\text { Putting on pants or a skirt while standing and } \\
\text { holding an object }\end{array}$ & Balancing ability & 0.809 & 0.186 & 0.060 & 0.731 & 5.8 & 21.7 & $15.9 \mathrm{~ns}$ \\
\hline $\begin{array}{l}\text { Standing on the bus or train (while holding } \\
\text { onto a hand strap or rail) }\end{array}$ & Balancing ability & 0.803 & 0.097 & 0.084 & 0.673 & 8.3 & 22.3 & $14.0 \mathrm{~ns}$ \\
\hline Walking $1 \mathrm{~km}^{\mathrm{a}}$ & Walking ability & 0.600 & 0.222 & 0.247 & 0.522 & 10.1 & 26.3 & $16.2 \mathrm{~ns}$ \\
\hline Using walking aids ${ }^{\mathrm{a}}$ & Walking ability & 0.785 & 0.116 & 0.124 & 0.656 & 4.4 & 20.6 & $16.2 \mathrm{~ns}$ \\
\hline Walking (about $20-40 \mathrm{~min}$ ) & Walking ability & 0.578 & 0.210 & 0.264 & 0.522 & 10.6 & 26.3 & $15.7 \mathrm{~ns}$ \\
\hline Pedestrian crossing & Walking ability & 0.559 & 0.054 & 0.069 & 0.336 & 6.9 & 19.4 & $12.5 \mathrm{~ns}$ \\
\hline Walk without walking aids & Walking ability & 0.525 & 0.032 & 0.172 & 0.294 & 3.9 & 12.0 & $8.1 \mathrm{~ns}$ \\
\hline Gait become staggering & Gait & 0.587 & 0.169 & 0.422 & 0.572 & 15.6 & 33.1 & $17.5 \mathrm{~ns}$ \\
\hline Walking straight on a single line & Gait & 0.506 & 0.215 & 0.211 & 0.372 & 13.4 & 26.9 & $13.5 \mathrm{~ns}$ \\
\hline Sit-up (1-2 times $)^{\mathrm{a}}$ & Muscular strength & 0.317 & 0.492 & 0.051 & 0.406 & 27.3 & 41.1 & $13.8 \mathrm{~ns}$ \\
\hline Folding up and down a heavy futon ${ }^{\mathrm{a}}$ & Muscular strength & 0.316 & 0.589 & 0.244 & 0.492 & 31.7 & 45.1 & $13.4 \mathrm{~ns}$ \\
\hline Sit-up (3-4 times) & Muscular strength & 0.160 & 0.651 & 0.101 & 0.438 & 56.8 & 68.0 & $11.2 \mathrm{~ns}$ \\
\hline Carrying (about $10 \mathrm{~kg}$ ) & Muscular strength & 0.298 & 0.617 & 0.099 & 0.431 & 38.6 & 49.7 & $11.1 \mathrm{~ns}$ \\
\hline Running $(3-5 \min )^{\mathrm{a}}$ & Walking ability & 0.364 & 0.475 & 0.345 & 0.466 & 30.8 & 42.3 & $11.5 \mathrm{~ns}$ \\
\hline Walking (about $60 \mathrm{~min})^{\mathrm{a}}$ & Walking ability & 0.159 & 0.514 & 0.352 & 0.399 & 48.5 & 59.4 & $10.9 \mathrm{~ns}$ \\
\hline Running (10 min or over) & Walking ability & 0.002 & 0.502 & 0.199 & 0.253 & 79.2 & 85.7 & $6.5 \mathrm{~ns}$ \\
\hline $\begin{array}{l}\text { Standing from sitting posture (Seiza) without } \\
\text { hands }^{\mathrm{a}}\end{array}$ & $\begin{array}{l}\text { Changing and holding } \\
\text { posture }\end{array}$ & 0.313 & 0.432 & 0.311 & 0.383 & 37.6 & 53.7 & $16.1 \mathrm{~ns}$ \\
\hline Jumping a gap (about $50 \mathrm{~cm})^{\mathrm{a}}$ & Lower limb strength & 0.280 & 0.582 & 0.263 & 0.458 & 38.1 & 48.0 & $9.9 \mathrm{~ns}$ \\
\hline $\begin{array}{l}\text { Buttoning or unbuttoning a shirt (with single } \\
\text { hand) })^{\mathrm{a}}\end{array}$ & Upper limb function & 0.038 & 0.553 & 0.025 & 0.232 & 64.5 & 72.0 & $7.5 \mathrm{~ns}$ \\
\hline $\begin{array}{l}\text { Climbing up stairs (without handrail and } \\
\text { wall) }^{\mathrm{a}}\end{array}$ & $\begin{array}{l}\text { Going and down } \\
\text { stairs }\end{array}$ & 0.209 & 0.538 & 0.471 & 0.507 & 44.5 & 64.0 & $19.5^{*}$ \\
\hline $\begin{array}{l}\text { Standing on the bus or train (without holding } \\
\text { onto a hand strap or rail) }\end{array}$ & Balancing ability & 0.140 & 0.606 & 0.267 & 0.389 & 58.0 & 70.3 & $12.3 \mathrm{~ns}$ \\
\hline One foot balance with open eyes $(\geq 30 \mathrm{~s})^{\mathrm{a}}$ & Balancing ability & 0.159 & 0.401 & 0.375 & 0.318 & 56.2 & 63.4 & $7.2 \mathrm{~ns}$ \\
\hline Short-stepped gait ${ }^{\mathrm{a}}$ & Gait & 0.190 & 0.189 & 0.678 & 0.470 & 38.1 & 59.4 & $21.3 *$ \\
\hline Slow-walking speed ${ }^{\mathrm{a}}$ & Gait & 0.137 & 0.221 & 0.739 & 0.518 & 42.9 & 64.0 & $21.1 *$ \\
\hline
\end{tabular}


Table 2 continued

\begin{tabular}{|c|c|c|c|c|c|c|c|c|}
\hline \multirow[t]{3}{*}{ Items } & \multirow[t]{3}{*}{ Sub-factor } & \multicolumn{4}{|c|}{ Factor analysis } & \multicolumn{3}{|c|}{ High-fall risk rate } \\
\hline & & \multicolumn{3}{|c|}{ Factor loading } & \multirow[t]{2}{*}{ Communality } & \multirow{2}{*}{$\begin{array}{l}\text { Non-faller } \\
(\%)\end{array}$} & \multirow{2}{*}{$\begin{array}{l}\text { Faller } \\
(\%)\end{array}$} & \multirow{2}{*}{$\begin{array}{l}\text { Difference } \\
(\%)\end{array}$} \\
\hline & & $\mathrm{F} 1$ & $\mathrm{~F} 2$ & F3 & & & & \\
\hline Take extra time to climb up and down stairs & $\begin{array}{l}\text { Going and down } \\
\text { stairs }\end{array}$ & 0.329 & 0.235 & 0.619 & 0.460 & 26.0 & 42.9 & $16.9 \mathrm{~ns}$ \\
\hline Assistance with going to the restroom & Walking ability & 0.109 & 0.133 & 0.302 & 0.097 & 0.8 & 4.0 & $3.2 \mathrm{~ns}$ \\
\hline Moving without assistance & Walking ability & 0.110 & 0.194 & 0.245 & 0.104 & 9.7 & 10.9 & $1.2 \mathrm{~ns}$ \\
\hline Staggering when turning around & Balancing ability & 0.288 & 0.238 & 0.042 & 0.198 & 25.1 & 36.6 & $11.5 \mathrm{~ns}$ \\
\hline Eigenvalue & & 9.14 & 4.74 & 3.34 & & & & \\
\hline Accumulative contribution & & $22.9 \%$ & $34.8 \%$ & $43.1 \%$ & & & & \\
\hline
\end{tabular}

Values in italics mean representative items of each factor

F1, Fundamental function; F2, advanced function; F3, gait; ns, not significant

$* P<0.05$

${ }^{\text {a }}$ Items selected as useful items

Table 3 The result of factor analysis on disease and physical symptoms

\begin{tabular}{|c|c|c|c|c|c|c|c|c|c|c|}
\hline \multirow[t]{3}{*}{ Items } & \multicolumn{7}{|c|}{ Factor analysis } & \multicolumn{3}{|c|}{ High-fall risk rate } \\
\hline & \multicolumn{6}{|c|}{ Factor loading } & \multirow[t]{2}{*}{ Communality } & \multirow{2}{*}{$\begin{array}{l}\text { Non- } \\
\text { faller } \\
(\%)\end{array}$} & \multirow{2}{*}{$\begin{array}{l}\text { Faller } \\
(\%)\end{array}$} & \multirow{2}{*}{$\begin{array}{l}\text { Difference } \\
(\%)\end{array}$} \\
\hline & $\mathrm{F} 1$ & $\mathrm{~F} 2$ & F3 & $\mathrm{F} 4$ & F5 & F6 & & & & \\
\hline Lightheadedness upon standing up ${ }^{a}$ & 0.773 & 0.018 & 0.130 & -0.019 & -0.031 & 0.055 & 0.323 & 19.8 & 33.1 & $13.3 \mathrm{~ns}$ \\
\hline Feel dizzy upon standing up ${ }^{a}$ & 0.817 & 0.070 & 0.051 & -0.010 & 0.007 & 0.012 & 0.354 & 14.4 & 26.9 & $12.5 \mathrm{~ns}$ \\
\hline $\begin{array}{l}\text { Feel light in one's head on standing up too } \\
\text { quickly }\end{array}$ & 0.578 & 0.072 & 0.158 & 0.256 & 0.102 & 0.028 & 0.217 & 12.1 & 24.0 & $11.9 \mathrm{~ns}$ \\
\hline Medication (daily) $^{\mathrm{a}}$ & 0.012 & 0.752 & 0.010 & 0.089 & 0.020 & 0.205 & 0.316 & 60.2 & 68.6 & $8.4 \mathrm{~ns}$ \\
\hline Circulatory disease $^{\mathrm{a}}$ & 0.041 & 0.796 & -0.029 & 0.170 & 0.028 & -0.048 & 0.354 & 37.5 & 45.7 & $8.2 \mathrm{~ns}$ \\
\hline $\begin{array}{l}\text { Medication (sleeping drugs, blood } \\
\text { pressure medications or tranquilizers) }\end{array}$ & 0.060 & 0.803 & 0.053 & -0.140 & 0.070 & -0.018 & 0.357 & 28.7 & 36.0 & $7.3 \mathrm{~ns}$ \\
\hline Forgetfulness $^{\mathrm{a}}$ & 0.218 & -0.005 & 0.553 & 0.138 & 0.197 & -0.074 & 0.130 & 51.3 & 67.4 & $16.1 \mathrm{~ns}$ \\
\hline Hearing disorder ${ }^{\mathrm{a}}$ & 0.098 & 0.062 & 0.590 & 0.002 & 0.045 & 0.138 & 0.087 & 26.0 & 35.4 & $9.4 \mathrm{~ns}$ \\
\hline Seeing disorder ${ }^{\mathrm{a}}$ & 0.142 & 0.019 & 0.696 & 0.088 & 0.031 & -0.042 & 0.116 & 28.0 & 37.1 & $9.1 \mathrm{~ns}$ \\
\hline Feel groggy ${ }^{a}$ & 0.296 & 0.069 & -0.130 & 0.689 & 0.083 & 0.027 & 0.150 & 3.6 & 8.6 & $5.0 \mathrm{~ns}$ \\
\hline Stroke $^{\mathrm{a}}$ & -0.160 & 0.033 & 0.243 & 0.740 & -0.028 & 0.078 & 0.084 & 1.4 & 4.0 & $2.6 \mathrm{~ns}$ \\
\hline Articular disorder ${ }^{\mathrm{a}}$ & 0.106 & 0.244 & 0.071 & 0.092 & 0.531 & -0.136 & 0.113 & 21.6 & 35.4 & $13.8^{*}$ \\
\hline Osteoporosis ${ }^{\mathrm{a}}$ & -0.062 & 0.024 & 0.071 & -0.012 & 0.776 & -0.004 & 0.074 & 13.2 & 17.7 & $4.5 \mathrm{~ns}$ \\
\hline Complications from a disease $^{\mathrm{a}}$ & 0.136 & 0.051 & 0.012 & 0.117 & 0.447 & 0.541 & 0.096 & 2.0 & 10.3 & $8.3 \mathrm{~ns}$ \\
\hline Diabetes $^{\mathrm{a}}$ & 0.012 & 0.053 & 0.004 & 0.031 & -0.077 & 0.847 & 0.056 & 8.8 & 9.7 & $0.9 \mathrm{~ns}$ \\
\hline Sleep disorder & 0.272 & 0.357 & 0.209 & -0.207 & 0.304 & 0.088 & 0.195 & 14.4 & 25.1 & $10.7 \mathrm{~ns}$ \\
\hline Fainted & 0.366 & 0.034 & -0.316 & 0.265 & 0.318 & -0.175 & 0.106 & 1.0 & 5.1 & $4.1 \mathrm{~ns}$ \\
\hline Eigenvalue & 2.04 & 2.06 & 1.42 & 1.31 & 1.35 & 1.15 & & & & \\
\hline Accumulative contribution & $12.0 \%$ & $24.1 \%$ & $32.4 \%$ & $40.1 \%$ & $48.1 \%$ & $54.8 \%$ & & & & \\
\hline
\end{tabular}

Values in italics mean representative items of each factor

F1, Dizziness and blackout; F2 medication; F3, sight/hearing and cognition disorder; F4, cerebral vascular disease; F5, arthritic and bone disease; F6, circulatory disease; ns, not significant

$* P<0.05$

${ }^{\text {a }}$ Selected items as useful items 
the difference in high-fall risk response rate from among the items showing high factor loading with each factor. However, in the seeing/hearing and cognition disorder factor, three items were selected in order to evaluate each sub-factor of sight disease, hearing disease and cognition disorder, respectively. Therefore, 13 items were selected as representative of disease and physical symptoms.

\section{Environment}

Table 4 shows the results of the factor analysis for the risk factor "environmental factor". Two factors explaining $38.8 \%$ of the variance were extracted. Taking factor loading matrix into account, the first and second factors were interpreted as the surrounding environment and clothing, respectively. Among the items showing high factor loading with each factor, the top two items in terms of the difference in percentage of high-fall risk response were selected. A total of the four items were selected as useful environmental items.

\section{Behavior and character}

Table 5 shows the results of the factor analysis for the risk factor "behavior and character". Four factors explaining $42.1 \%$ of the variance were extracted. Based on the factor loading matrix, we interpreted these factors as inactivity (the first factor), risk behavior A (the second factor), fear of fall (the third factor), and risk behavior B (the fourth factor). The factors of "risk behavior A" and "risk behavior B" comprised items representing toilet activities at night and acting cautiously, and climbing up a steep slope and rushing everywhere, respectively. Among the items showing high factor loading with each factor, the top two items in terms of the difference in percentage of high-fall risk response were selected. Eight items were selected as useful behavior and character items.

A total of 50 items were ultimately selected from each fall risk factor (symptoms of falling, 3 items; physical function, 22 items; disease and physical symptoms, 13 items; environment, 4 items; behavior and character, 8 items) (Table 6).

\section{Discussion}

Falls in the elderly are influenced by multiple factors and the cause (source) of falls in individuals also varies; consequently, fall risk assessments should be carried out comprehensively [3, 7-9]. In addition, in order to associate fall risk assessment with fall prevention, both fall risk level and fall risk characteristics (risk profile for individuals) should be assessed. Here, we have attempted to comprehensively assess fall risk in an healthy elderly Japanese population based on the assumption that fall risk comprises symptoms of falling, physical function, disease and physical symptoms, environment, and behavior and character. The TMIG fall risk assessment chart is composed of 15 items representing fall experience, physical function (4 items from walking ability, balancing, muscular strength), disease (7 items; hospitalization, medication, lightheadedness, stroke, diabetes, seeing and hearing disorder), environment ( 2 items; clothing, surrounding environment), and fear of falling.

One characteristic of the fall risk assessment in this study is the hypothesis construction of a fall risk factor that assumed symptoms of falling to be a dependent fall risk

Table 4 The result of factor analysis in environment

\begin{tabular}{|c|c|c|c|c|c|c|}
\hline \multirow[t]{3}{*}{ Items } & \multicolumn{3}{|c|}{ Factor analysis } & \multicolumn{3}{|c|}{ High-fall risk rate } \\
\hline & \multicolumn{2}{|c|}{ Factor loading } & \multirow[t]{2}{*}{ Communality } & \multirow[t]{2}{*}{ Non-faller $(\%)$} & \multirow[t]{2}{*}{ Faller $(\%)$} & \multirow[t]{2}{*}{ Difference $(\%)$} \\
\hline & $\mathrm{F} 1$ & $\mathrm{~F} 2$ & & & & \\
\hline Slippery places ${ }^{\mathrm{a}}$ & 0.636 & -0.060 & 0.132 & 16.3 & 24.0 & $7.7 \mathrm{~ns}$ \\
\hline Obstacle $^{a}$ & 0.732 & 0.044 & 0.200 & 25.2 & 31.4 & $6.2 \mathrm{~ns}$ \\
\hline House tidy & 0.397 & 0.318 & 0.074 & 19.4 & 24.6 & $5.2 \mathrm{~ns}$ \\
\hline Dark places in your house & 0.679 & 0.034 & 0.163 & 22.6 & 27.4 & $4.8 \mathrm{~ns}$ \\
\hline Uneven floors in your house & 0.481 & -0.151 & 0.066 & 76.4 & 79.4 & $3.0 \mathrm{~ns}$ \\
\hline Sandals or slippers ${ }^{\mathrm{a}}$ & 0.160 & -0.502 & 0.025 & 60.1 & 61.7 & $1.6 \mathrm{~ns}$ \\
\hline Shoes fit ${ }^{\mathrm{a}}$ & 0.025 & 0.684 & 0.045 & 2.9 & 3.4 & $0.5 \mathrm{~ns}$ \\
\hline Length of pants fit & 0.044 & 0.660 & 0.043 & 4.6 & 5.1 & $0.5 \mathrm{~ns}$ \\
\hline Eigenvalue & 1.820 & 1.286 & & & & \\
\hline Accumulative contribution & $22.7 \%$ & $38.8 \%$ & & & & \\
\hline
\end{tabular}

Values in italics mean representative items of each factor

F1, Surrounding environment; F2, clothing; ns, not significant

a Selected items as useful items 
Table 5 The result of factor analysis on behavior and character

\begin{tabular}{|c|c|c|c|c|c|c|c|c|}
\hline \multirow[t]{3}{*}{ Items } & \multicolumn{5}{|c|}{ Factor analysis } & \multicolumn{3}{|c|}{ High-fall risk rate } \\
\hline & \multicolumn{4}{|c|}{ Factor loading } & \multirow[t]{2}{*}{ Communality } & \multirow[t]{2}{*}{ Non-faller $(\%)$} & \multirow[t]{2}{*}{ Faller $(\%)$} & \multirow[t]{2}{*}{ Difference $(\%)$} \\
\hline & $\mathrm{F} 1$ & $\mathrm{~F} 2$ & $\mathrm{~F} 3$ & F4 & & & & \\
\hline Sit at home ${ }^{a}$ & 0.734 & -0.153 & -0.187 & -0.071 & 0.412 & 13.9 & 25.7 & $11.8 \mathrm{~ns}$ \\
\hline Go out on only rare occasions ${ }^{\mathrm{a}}$ & 0.777 & -0.114 & -0.117 & -0.021 & 0.458 & 6.7 & 14.9 & $8.2 \mathrm{~ns}$ \\
\hline Inactivity & 0.456 & -0.082 & -0.372 & -0.013 & 0.210 & 4.6 & 9.1 & $4.5 \mathrm{~ns}$ \\
\hline Participate in public events & 0.486 & 0.173 & 0.231 & -0.175 & 0.094 & 43.5 & 42.9 & $-0.6 \mathrm{~ns}$ \\
\hline Have many occasions to go out & -0.784 & 0.087 & 0.095 & 0.111 & 0.468 & 86.1 & 81.1 & $-5.0 \mathrm{~ns}$ \\
\hline Go to the toilet at night ${ }^{\mathrm{a}}$ & 0.125 & -0.759 & 0.028 & -0.067 & 0.232 & 36.3 & 46.9 & $10.6 \mathrm{~ns}$ \\
\hline Act cautiously ${ }^{\mathrm{a}}$ & 0.141 & 0.474 & 0.195 & 0.105 & 0.075 & 24.0 & 34.3 & $10.3 \mathrm{~ns}$ \\
\hline Go to the toilet frequently & 0.198 & -0.748 & -0.016 & 0.012 & 0.255 & 17.8 & 28.0 & $10.2 \mathrm{~ns}$ \\
\hline Confident about not falling $^{\mathrm{a}}$ & 0.194 & 0.010 & -0.715 & -0.136 & 0.255 & 30.5 & 61.1 & $30.6^{*}$ \\
\hline Fear of falling ${ }^{\mathrm{a}}$ & 0.340 & -0.264 & -0.589 & 0.021 & 0.290 & 20.3 & 36.6 & $16.3 \mathrm{~ns}$ \\
\hline Keep calm on a daily basis & 0.036 & 0.192 & -0.566 & -0.076 & 0.114 & 9.6 & 22.3 & $12.7 \mathrm{~ns}$ \\
\hline Climb up steep slope ${ }^{a}$ & 0.021 & 0.056 & -0.032 & 0.621 & 0.086 & 17.6 & 19.4 & $1.8 \mathrm{~ns}$ \\
\hline Rush everywhere $^{\mathrm{a}}$ & -0.169 & 0.120 & 0.007 & 0.470 & 0.107 & 32.7 & 32.6 & $-0.1 \mathrm{~ns}$ \\
\hline Go out on a rainy or snowy day & -0.237 & 0.006 & 0.120 & 0.668 & 0.219 & 41.7 & 41.1 & $-0.6 \mathrm{~ns}$ \\
\hline Go out at night & -0.022 & 0.036 & 0.112 & 0.496 & 0.064 & 8.4 & 7.4 & $-1.0 \mathrm{~ns}$ \\
\hline Climb the stairs & -0.071 & 0.044 & 0.221 & 0.439 & 0.091 & 52.6 & 48.0 & $-4.6 \mathrm{~ns}$ \\
\hline Hospitalization in the preceding year & 0.122 & -0.207 & -0.140 & -0.099 & 0.053 & 8.1 & 20.0 & $11.9 \mathrm{~ns}$ \\
\hline Communicate with many people & 0.368 & -0.063 & 0.303 & -0.199 & 0.072 & 13.2 & 10.3 & $-2.9 \mathrm{~ns}$ \\
\hline Eigenvalue & 2.67 & 1.62 & 1.66 & 1.63 & & & & \\
\hline Accumulative contribution & $14.8 \%$ & $23.8 \%$ & $33.0 \%$ & $42.1 \%$ & & & & \\
\hline
\end{tabular}

Values in italics mean representative items of each factor

F1, Inactivity; F2, risk behavior A; F3, fear of fall; F4, risk behavior B; ns, not significant

$* P<0.05$

a Selected items as useful items

factor. The TMIG fall risk assessment chart includes fall experience but not symptoms of falling. In general, fall experience has been treated as an important and valid criterion in fall risk assessments. Thus, we assessed fall risk from risk factors showing a significant relationship with fall experience, and risk level was determined by an integrated score of these risk factors. The TMIG fall risk assessment chart also takes the same position $[5,6]$. However, because multiple factors come into play in a complicated manner when an elderly person falls, it is not necessarily possible to reflect the level of fall risk with a total score which is simply an integration of item scores. This is especially true in the non-handicapped and healthy community-dwelling elderly, among whom there are many cases where there is no apparent disease that could decisively influence the occurrence of a fall and there are broad individual differences. On the other hand, symptoms of falling (the state of being liable to fall and its levels) are greatly influenced by various other risk factors of falling, and these can be interpreted as the precursor of a fall. Therefore, although symptoms of falling could not provide a detailed fall risk profile, a comprehensive fall risk level could be obtained by combining symptoms of falling with fall experiments. Based on the assumption that there are individual differences in the fall risk profile, we should assess the comprehensive fall risk level as being dependent on the severity of "the state of being liable to fall," and establish a fall risk profile from risk factors causing "the state of being liable to fall" in individuals [9].

One additional characteristic of our fall risk assessment is an enrichment of the physical function assessment items. Based on the assumption that there is no person with a severe disease in a healthy elderly population, we focused the fall prevention measurement after fall risk assessment primarily on an improvement in physical function. The provision of personal information on fall risk and personal physical function characteristics will make it possible to develop personal fall prevention measurements [11-14]. The TMIG fall risk assessment chart has only four items associated with walking ability, balancing, and muscular strength, which may limit the comprehensive assessment of physical function characteristics. For this reason, in this study we assessed physical function using several subfactors: balancing, muscular strength, lower limb strength, 
Table 6 Selected items in this study

\begin{tabular}{lll}
\hline Risk factors & Extracted factors & Sub-factors \\
\hline Symptoms of falling & Symptoms of falling & \\
& \\
Physical function & $\begin{array}{c}\text { Fundamental } \\
\text { function }\end{array}$ & Muscular strength
\end{tabular}

Lower limb strength

Balancing ability

Walking ability

Going and down stairs

Changing and holding posture

Upper limb function

Advanced function

Muscular strength

Lower limb strength

Balancing ability

Walking ability

Going and down stairs posture

Upper limb function

Gait

Gait

Dizziness and blackout
Changing and holding

Items

In the past year, have you felt like you might fall down? [Felt like falling in the preceding year]

Have you often stumbled? [Stumble]

Have you ever been told that you look like you might fall down? [Look like falling (third-party evaluation)]

Are you strong enough to wring out a wet towel or cloth effectively? [Wringing out a wet towel] ${ }^{\mathrm{c}}$

Can you carry a object weighing about $5 \mathrm{~kg}$ ? [Carrying (about $5 \mathrm{~kg})]$

Can you jump about a $30 \mathrm{~cm}$ gap? [Jumping about a $30-\mathrm{cm}$ ditch]

Can you stand on one foot and put a sock on the other foot? [Standing on one foot to put on a sock] $]^{\mathrm{c}}$

Can you stand on one foot about $5 \mathrm{~s}$ ? [Standing with one foot (about $5 \mathrm{~s}$ )]

Can you walk continuously for about $1 \mathrm{~km}$ ? [Walking $1 \mathrm{~km}]^{\mathrm{c}}$

Do you usually use walking aids such as stick or walker?

[Using walking aids]

Can you climb up stairs slowly without a handrail or wall for support? [Climbing up stairs slowly without a handrail or wall]

Can you stand from a sitting posture (Seiza) with your hands on the floor? [Standing from sitting posture(Seiza) with hands on the floor]

Can you button or unbutton a shirt quickly with both hands? [Buttoning or unbuttoning a shirts (quickly with hands)]

Can you sit-up about 1-2 times? [Sit-up (1-2 times)]

Can you fold up and down a heavy futon? [Folding up and down a heavy futon (heavy futon)]

Can you jump about a $50 \mathrm{~cm}$ gap? [Jumping a gap (about $50 \mathrm{~cm}$ )]

Can you stand on the bus or train without holding onto a hand strap or rail? [Standing on the bus or train (without holding onto a hand strap or rail)]

Can you balance on one foot with open eyes for $30 \mathrm{~s}$ or more? [One foot balance with open eyes ( $30 \mathrm{~s}$ or more)]

Can you run about 3-5 min? [Running (3-5 min)]

Can you walk about $60 \mathrm{~min}$ ? [Walking (about $60 \mathrm{~min}$ )]

Can you climb up stairs without a handrail and wall for support? [Climbing up stairs (without handrail and wall)]

Can you stand from a sitting posture (Seiza) without using your hands? [Standing from sitting posture (Seiza) without hands)]

Can you button or unbutton a shirt with single hand?

[Buttoning or unbuttoning a shirt (with single hand)]

Do you feel your length of stride decrease? [Short-stepped gait]

Do you feel your walking speed becoming slower? [Slowwalking speed]

Do you ever feel lightheaded upon standing up?

[Lightheadedness upon standing up $]^{\mathrm{c}}$

Do you ever feel dizzy upon standing up? [Feel dizzy upon standing up]

Medication
Are you taking any medications, daily? [Medication (daily)] ${ }^{\mathrm{c}}$

Have you ever had a circulatory disease? [Circulatory disease] 
Table 6 continued

\begin{tabular}{|c|c|c|c|}
\hline Risk factors & Extracted factors & Sub-factors & Items \\
\hline & $\begin{array}{l}\text { Sight/hearing and cognition } \\
\text { disorder }\end{array}$ & $\begin{array}{r}\text { Cognition } \\
\text { disorder }\end{array}$ & Do you feel forgetful these days? [Forgetfulness] \\
\hline & & Hearing disorder & Can you hear well (people talking, etc.)? [Hearing disorder $]^{\mathrm{c}}$ \\
\hline & & Seeing disorder & $\begin{array}{l}\text { Can you see well (newspaper, people's faces, etc.)? [Seeing } \\
\text { disorder] }\end{array}$ \\
\hline & Cerebral vascular & & Do you ever feel groggy? [Feel groggy] \\
\hline & & & Have you ever had a stroke? $[\text { Stroke }]^{\mathrm{c}}$ \\
\hline & Arthritic and bone disease & & 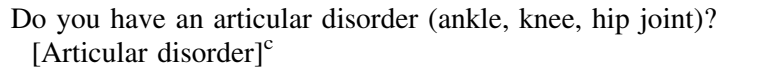 \\
\hline & & & Do you have osteoporosis? [Osteoporosis] \\
\hline & Circulatory disease & & $\begin{array}{l}\text { Have you ever had complications from a disease? } \\
\text { [Complications from a disease] }\end{array}$ \\
\hline & & & Have you ever been diagnosed as having diabetes? [Diabetes] ${ }^{\mathrm{c}}$ \\
\hline \multirow[t]{4}{*}{ Environment } & Surrounding environment & & Are there slippery places in your house? [Slippery places] \\
\hline & & & $\begin{array}{l}\text { Are there obstacles that may cause someone to stumble in your } \\
\text { house? [Obstacle] }\end{array}$ \\
\hline & Clothing & & $\begin{array}{l}\text { Do you wear sandals or slippers a lot every day? [Sandals or } \\
\text { slippers] }^{c}\end{array}$ \\
\hline & & & Do Your shoes fit your feet? [Shoes fit] \\
\hline \multirow{8}{*}{$\begin{array}{c}\text { Behavior and } \\
\text { Character }\end{array}$} & Inactivity & & Do you often sit at home? [Sit at home] \\
\hline & & & $\begin{array}{l}\text { Do you hardly ever have occasions to go out? [Go out on only } \\
\text { rare occasions] }\end{array}$ \\
\hline & Risk behavior $\mathrm{A}^{\mathrm{a}}$ & & $\begin{array}{l}\text { Do you have many occasions to go to the toilet at night? [Go to } \\
\text { the toilet at night] }\end{array}$ \\
\hline & & & Do you act cautiously? [Act cautiously] \\
\hline & Fear of falling & & $\begin{array}{l}\text { Are you confident about not falling? [Confident about not } \\
\text { falling] }\end{array}$ \\
\hline & & & Do you worry about falling? [Fear of falling $]^{\mathrm{c}}$ \\
\hline & Risk behavior $\mathrm{B}^{\mathrm{b}}$ & & Do you often climb up the steep slope? [Climb up steep slope] \\
\hline & & & Do you often rush about? [Rush everywhere] \\
\hline Fall experience & & & $\begin{array}{l}\text { In the past year, have you slipped or stumbled and then fallen } \\
\text { down? [Fall in the preceding year] }{ }^{\text {c }}\end{array}$ \\
\hline
\end{tabular}

A comprehensive fall risk level can be obtained by combining symptoms of falling with fall experiments Items in square parenthesis are the short label of each item

a The factors of "Risk behavior A" are represented by going to the toilet at night and acting cautiously

b The factors of "Risk behavior B" are represented by climbing up steep slope and rush everywhere

c Items used in the Tokyo Metropolitan Institute of Gerontology (TMIG) assessment chart

walking ability, going up and down stairs, holding and changing posture, and upper limbs function. According to the results of factor analysis, two factors on physical function (fundamental function factor and advanced function factor) could be interpreted based on the achievement (difficulty) level of the activities rather than the independence of the physical function component. In this study, representative items of each factor were selected from all sub-factors constructing each factor. Thus, the physical function assessment items in this study can assess physical function level gradually using assessment items of different degrees of difficulty in addition to comprehensively assessing physical function characteristics. Take balancing, for example, we can gradually assess the ability level by using two different difficulty items, such as "can you stand on one leg for $5 \mathrm{~s}$ " and "can you stand on one leg for 30 s." Consequently, our assessment protocol has a great potential for application in various elderly populations with a broad functional level and differences in intra-individual changes in physical function.

In each of the other risk factors (diseases and physical symptom, environment, behavior and character), we were also able to select two or more items from multiple subfactors and assess fall risk characteristics comprehensively. 
As mentioned above, in fall risk assessment, it is important to recognize fall risk characteristics from outcomes and to determine a personal fall prevention measurement. In that context, the selected assessment items in this study are useful for establishing a personal fall risk profile. The selected items in this study have more items than the TMIG assessment chart, although they do include ten items from it. However, these are required to assess both fall risk level and the fall risk profile.

In the Introduction, we indicated that there were a number of problems associated with the TMIG assessment chart that need to be improved: (1) it is composed of multiple factorial components, but it is unbalanced; (2) there are many items on disease, which are difficult to improve over the short term, but there are only a few items on physical function, which may be improved; (3) it is difficult to use for a comprehensive and gradual assessment of physical function. In this study, we have developed an assessment system for improving upon the TMIG assessment chart in which we incorporate 50 items representing risk factors, including symptoms of falling, physical function, disease and physical symptoms, environment, and behavior and character. These items can be used to comprehensively assess fall risk in a healthy elderly population. Furthermore, these assessment items on physical function were items with different levels of difficulty that had been selected from the sub-factors of balancing, muscular strength, lower limb strength, walking ability, holding and changing posture, upper limb function, and they can gradually and comprehensively assess physical function.

In conclusion, this study goes no further than to propose useful items for assessment purposes. Further studies are required to examine the validity of these items and to examine assessment methods and criteria for a comprehensive fall risk level and fall risk characteristics based on these items. Taking into account both the current perspective on fall risk assessment and the methods for utilizing the items proposed in this study, a comprehensive fall risk level could be assessed on the basis of symptoms of falling and fall experiments if we were to make simplicity the top priority. The items representing other risk factors could then be used to further establish the fall risk profile of each subject. Our selected items on physical function may therefore be useful in longitudinal assessments of the healthy elderly population.
Acknowledgment This work was supported by a Grant-in-Aid for Scientific Research, the Japan Ministry of Education, Culture, Sports, Science and Technology [grant number 21240064].

\section{References}

1. Costello E, Edelstein JE. Update on falls prevention for community-dwelling older adults: review of single and multifactorial intervention programs. J Rehabil Res Dev. 2008;45:1135-52.

2. Soriano TA, Decherrie LV, Thomas DC. Falls in the communitydwelling older adult: a review for primary-care providers. Clin Interv Aging. 2007;2:545-54.

3. Pluijm SMF, Smit JH, Tromp EAM, Stel VS, Deeg DJH, Bouter $\mathrm{LM}$, et al. A risk profile for identifying community-dwelling elderly with a high risk of recurrent falling: results of a 3-year prospective study. Osteoporos Int. 2006;17:417-25.

4. Campbell AJ, Borrie MJ, Spears GF, Jackson SL, Brown JS, Fitzgerald TL. Circumstances and consequences of falls experienced by a community population 70 years and over during a prospective study. Age Ageing. 1990;19:136-41.

5. Suzuki T. Epidemiology and implications of falling among the elderly (in Japanese). Nippon Ronen Igakkai Zasshi. 2003;40:8594.

6. Suzuki T. Questionnaire for falls assessment of elderly people and its application. Health assessment manual (in Japanese). Tokyo: Kosei Kagaku Kenkyusho; 2000. p. 142-63.

7. Russell MA, Hill KD, Day LM, Blackberry I, Gurrin LC, Dharmage SC. Development of the falls risk for older people in the community (FROP-Com) screening tool. Age Ageing. 2009;38:40-6.

8. Perell KL, Nelson A, Goldman RL, Luther SL, Prieto-Lewis N, Rubenstein LZ. Fall risk assessment measures: an analytic review. J Gerontol. 2001;56:M761-6.

9. Graafmans WC, Ooms ME, Hofstee HMA, Bezemer PD, Bouter LM, Lips P. Falls in the elderly: a prospective study of risk factors and risk profiles. Am J Epidemiol. 1996;143:1129-36.

10. Schenkman M, Riegger-Krugh C. Physical intervention for elderly patients with gait disorders. Gait disorders of aging. In: Masdeu JC, Sudarsky L, Wolfson L, editors. Philadelphia: Lippincott-Raven; 1997. p. 327-53.

11. Yokoya T, Demura S, Sato S. Three-year follow-up of the fall risk and physical function characteristics of the elderly participating in a community exercise class. J Physiol Anthropol. 2009;28:55-62.

12. Yokoya T, Demura S, Sato S. Fall risk characteristics of the elderly in an exercise class. J Physiol Anthropol. 2008;27:25-32.

13. Laessoe U, Hoeck HC, Simonsen O, Sinkjaer T, Michael V. Fall risk in an active elderly population-can it be assessed? J Negat Results BioMed. 2007; 6. doi: 10.1186/1477-5751-6-2, see http://www.jnrbm.com/content/6/1/2.

14. Robertson MC, Campbell AJ, Gardner MM, Devlin N. Preventing injuries in older people by preventing falls: a meta-analysis of individual data. J Am Geriatr Soc. 2002;50:905-11. 